\title{
INTERSTÍCIOS DA MATÉRIA
}

\author{
Anais Alves Pereira ${ }^{1}$
}

Resumo: $O$ artigo relaciona o conceito $M a$ e o interstício, em Aby Warburg, constituindo relações temporais e espaciais não-lineares entre o sertão brasileiro e o nordeste japonês. A partir da palavra Shizen, são discutidos os limites entre serhumano e natureza, traçando um percurso em busca de compreender as fronteiras como intervalo que conecta opostos.

Palavras-chave: Ma. Natureza. Sertão. Fronteira.

\section{INTERSTICES OF MATTER}

\begin{abstract}
The article relates the Ma concept and the interstice in Aby Warburg, constituting nonlinear temporal and spatial relations between the Brazilian sertão and the Japanese northeast. From the word Shizen, the boundaries between beinghuman and nature are discussed, tracing a path in search of understand the boundaries as an interval that connects opposites.
\end{abstract}

Keywords: Ma. Nature. Sertão. Boundaries.

O caractere japonês $M a$ 間 quando sozinho pode ser pronunciado como aida e denota não apenas a distância em linha reta entre dois pontos no espaço, mas

\footnotetext{
${ }^{1}$ Anais-karenin é artista e pesquisadora, seu trabalho discorre sobre as relações com a natureza e seus contrastes com os materiais artificiais a partir de instalações, esculturas e performances. Doutoranda em Poéticas Visuais pelo PPGAV/ECA-USP e mestre em Artes pelo PPGArtes/UERJ, realizou trabalhos no Japão e estudos em dança butoh. Expos em espaços como OMISE e MIIT House (Japão), CMAHO, Paço Imperial, Oi Futuro, entre outros. Participou dos salões 14o SNAI e 15o Salão de Artes de Ubatuba.
} 
também uma consciência simultânea de ambos os pólos. Há uma peculiar ambivalência nesse caractere, que se expressa nessa interpretação onde 間 pode significar "distância" ou "interstício", "polaridade" ou "relatividade". Nessa interpretação, a distância entre as coisas pode ser também o ponto de encontro entre elas (interstício), e as características que as tornam opostas podem ser entendidas como uma sendo o ponto de referência para interpretação e compreensão da outra.

O Ma designa essa noção de "entre". É um conceito que conjuga espaço e tempo apontando uma noção intervalar extremamente presente em diversas áreas da cultura japonesa, bem como as artes, a arquitetura, a literatura, entre outros. Há também a interpretação desse termo como o "vazio" ou o "nada" que se forma nesse intervalo "entre", sendo o vazio um espaço que pode ser ocupado por qualquer coisa. Nesse sentido, o espaço vazio $(M a)$ se configura também como um lugar de formulações de subjetividades fluidas, como ponto de encontro da diferença, percepção de que tudo é destituído de um "eu" e todas as coisas são interconectadas por esse ponto vazio, transitório. Temos o vazio do "entre" mais como uma experiência de força simbólica e imaginativa do que como um conceito físico.

A partir dessa experiência extra-matéria, que não é delimitada pela forma mas pelo entre-forma, surge o potencial de se conectar com aspectos imateriais, cósmicos e transcendentais. $\mathrm{O}$ vazio do $M a$ não demarca a falta, mas caracteriza-se como um espaço onde ocorre a mudança e a transformação. É possível executar o espaço vazio do in-between como uma forma de associar e fundir coisas completamente diferentes, assim como o historiador Aby Warburg executa em seus mapas de imagens, o intervalo e a intersecção que conecta.

Aby Warburg (2010) foi um pesquisador do Renascimento florentino durante boa parte de sua vida. Quando viajou para o Oeste norte-americano, entre 1895 e 1896, permaneceu no Arizona e Novo México e conheceu as populações hispano-indígenas da região, adentrando os rituais dos índios hopis. Sua compreensão da arte nessa experiência mudou profundamente, pois, ali, Warburg detectou manifestações 
artísticas dentro de um campo prático da vida, onde a relação entre arte e religião se estreitavam. Após permanecer trinta anos sem falar sobre sua experiência com os indígenas, Warburg trouxe o assunto a público em uma conferência na qual ele colidiu a realidade indígena e florentina interpretando o passado a partir da justaposição de camadas de realidade estranhas uma a outra de modo que pudessem se justificar mutuamente, pelo interstício. A partir da leitura de Aby Warburg é possível constituir uma relação não linear com a história e ultrapassar os limites territoriais e temporais que separam diferentes manifestações culturais. 0 historiador da arte Philippe-Alain Michaud explica que:

\footnotetext{
Essa aproximação abrupta não decorre da simples comparação, mas da distância, da detonação, da deflagração: não almeja evidenciar invariantes em meio a ordens de realidade heterogêneas, mas introduzir a diferença e a alteridade no seio da identidade. (MICHAUD, 2013, p. 295)
}

O modo de lidar com a memória social revela uma decisão ética e define "a posição dos indivíduos e de uma época em relação à herança do passado"i. A sociedade ocidental, fazendo de sua história o motor de seu desenvolvimento, alterou a memória social, gerando rememorações e esquecimentos estratégicos acerca da tradição cultural. De acordo com o crítico Shuichi Kato (2011), a consciência histórica ocidental se originou do tempo judaico, o qual flui sobre uma linha reta que vai do começo para o fim em uma única direção, influenciado pela crença judaica na "Terra Prometida", para onde se deveria seguir abandonando tudo o que houvesse pelo caminho e tudo o que houve antes (abandonar todos os deuses e servir a um Deus único). Portanto, nessa noção temporal, "parece impossível falar sobre a relação do que vem antes com o que vem depois de um acontecimento e tampouco relacionar os acontecimentos atuais aos do passado"ii.

Nessa compreensão histórica repousam inúmeros apagamentos culturais, que deslocam nossas práticas cotidianas, investigações científicas, tecnológicas, intelectuais e artísticas das matrizes indígenas, nordestinas, e apagam a conexão que há entre um tempo histórico e outro, um território e outro, como se apenas a distância pudesse ser vista e não o ponto de encontro. Como resultado não só de uma colonização que violou essas matrizes mas que também impregnou essa noção 
histórica retilínea nas novas gerações, desconectando-as de qualquer passado possível, especialmente o passado que não está territorialmente localizado nos arredores.

O que Aby Warburg ativa é a retomada e a ampliação das fronteiras da história, ao incorporar valores expressivos "primitivos", cósmicos e heterogêneos em suas interpretações. Nesse sentido, quando Warburg demonstra compreender a arte florentina a partir dos aprendizados que adquiriu com os índios hopis, ele desmembra estruturas rígidas como se elaborasse uma dança que desloca fronteiras. Ao mesmo tempo, seu trabalho não assume um posicionamento rígido, mas se faz na passagem $M a$, nas possíveis conexões que pode fazer no deslocamento de uma imagem a outra, um tempo histórico a outro, uma cultura a outra.

Podemos, então, nos propor a visualizar o tempo como se fosse uma espiral na qual o passado, o presente e o futuro possam formar pontos conectivos assimiláveis. Com a passagem do tempo, a linha da espiral aumenta, fazendo com que o passado mais longínquo fique em paralelo com o presente mais recente, mesmo que hajam camadas e mais camadas de linhas e acontecimentos entre esses dois tempos. À medida que a linha cresce mais, a espiral vai se afunilando até chegar a um ponto em que as linhas paralelas quase se encostam, se atravessam ou se transpõem. Essa imagem do tempo em espiral expressa as conexões mais profundas que os humanos têm com os elementos, com a memória de outros períodos históricos, com a natureza, com outros seres e saberes invisíveis. Quanto maior a distância temporal, maior também a chance do corpo tocar em múltiplas camadas de tempo e ser atravessado por ela. 


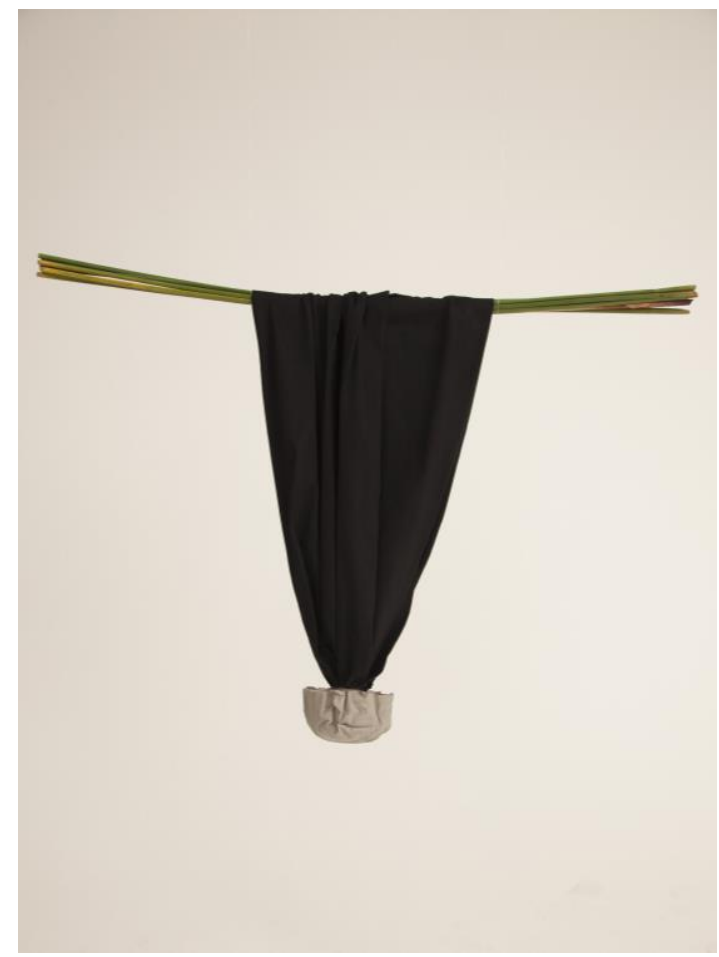

Autor: Anais-karenin; Título: Reinforcement; Técnica: Objeto; Dimensões: 60x40cm; Fonte: registro por Cassia Tabatini

Traçando um outro caminho nessa reflexão, o designer e curador japonês Kenya Hara, em sua palestra Era of Nomad / Tradition as Future convoca os paradigmas da tradição e da modernidade partindo de uma análise sobre a cultura japonesa. Segundo Hara, a tradição não necessariamente reside no passado; ela é também um conceito importante para o estabelecimento do futuro. Sua reflexão parte da aproximação dos conceitos de globalismo e localismo, colocando a diversidade e particularidades de cada cultura como uma chave para o desenvolvimento de uma cultura mundial. Ou seja, considerando a importância dos valores tradicionais de cada cultura, é possível estar mais próximo de um mundo com fronteiras menos rígidas e delimitadas. Refletindo sobre a forte presença das tradições na formação da cultura, o dualismo tecnologia versus natureza também é colocado em questão. Neste ponto, Hara propõe que o desenvolvimento da tecnologia caminhe em conjunto com a natureza.

Mas o que seria essa "natureza"? Quando falamos de "natureza", convocamos algo ao mesmo tempo concreto e abstrato, material e conceitual, físico e metafísico. "Natureza" pode remeter a uma paisagem paradisíaca e tropical, a um lugar intocado e reservado tomado por florestas densas. Por fim, ela engloba tanto os elementos 
que povoam essas paisagens quanto as forças invisíveis que as movem, a essência, a conotação da eternidade que torna as coisas o que são.

Uma das múltiplas perspectivas sobre o que é "natureza" está contida na palavra Shizen 自然, que expressa uma ampla cosmovisão oriental incutida de paradigmas que foram se modificando ao longo do tempo. Shizen seria a tradução mais aproximada de Nature, no entanto esses termos expressam diferentes visões. Shizen significava uma série de relações macro-micro-cósmicas onde não se excluíam nem separavam claramente a esfera humana, o reino das ideias, ou mesmo o reino dos seres sobrenaturais, da matéria, do material, do ambiente. Diferentemente disso, a palavra nature forma uma série de relações dialéticas: "natureza" versus "criação", versus "cultura", versus "história"; "natural" versus "artificial". Essas relações separam um reino (de coisas, processos, forças, imagens, conceitos) de outro, que é a província dos seres humanos.

É possível observar, portanto, que a concepção de natureza sempre muda em distintos contextos sociais e culturais. Consequentemente, a mudança em seu entendimento modifica todas as esferas na qual o termo se estabelece. Como resultado, as práticas intelectuais, artísticas, políticas, econômicas, secularizaram a natureza como "objeto", que pode ser apreendido, manipulado, possuído e trocado. Muitas vezes, a própria ideia concebida de natureza impede que haja o desenvolvimento de uma compreensão mais profunda da relação humana com o meio ambiente material e imaterial, da relação entre natureza e cultura e, especialmente, das relações entre as diferentes culturas. Nesse sentido, a diferença é entendida como separação, intensificando o espaço físico e simbólico que divide as coisas.

O antropólogo Bruno Latour (2011) discute a crescente separação entre humano e meio ambiente a partir do uso do termo cosmopolítica ou política do cosmos, empregado por Isabelle Stengers, que propõe um equilíbrio entre os termos "cosmos", "que garante que a política nunca será apenas para os benefícios de humanos isolados"iii, e "política", "que assegura que o cosmos não é naturalizado e 
mantido totalmente à parte do que os humanos fazem a ele". 0 que mais importa aqui é que os seres humanos não sejam definidos sem os cosmos do qual provém a manutenção de sua existência, e que a natureza não seja definida sem os humanos que colaboraram com não-humanos. Falar de cosmopolítica é dizer que o mundo tem que ser composto. 0 desenvolvimento da ética cósmica, de uma política cósmica, da composição apontada por Latour, seriam estratégias que se ancoram em uma percepção extremamente básica de que os seres humanos são parte de um todo regulado por essa misteriosa e complexa natureza inanimada.

No animismo, a visão de mundo compreende que as entidades não-humanas possuem espírito, e que as forças espirituais têm poder sobre os assuntos humanos e que aquelas determinam o futuro destes, passando pela relação com seres inanimados, objetos e fenômenos naturais, esses últimos especialmente regulando um poder sobrenatural e mágico. Para a perspectiva animista, parte da cosmovisão de muitas etnias indígenas e de algumas religiões como o Xintoísmo, o mundo espiritual está acima do mundo material e controla todos os acontecimentos. Esse pensamento que rompe fronteiras e hierarquias entre o mundo espiritual e material também transpassa as fronteiras da matéria, dos seres, dos territórios e das culturas.

O artista japonês Kishio Suga, integrante do grupo de arte pós-guerra Mono-Ha, baseia suas criações na conexão entre diferentes elementos através da interdependência mútua que eles estabelecem, reverberando uma dimensão anímica em seu processo criativo. A existência de cada coisa no mundo já é, para Suga, algo único e original e o seu desejo é deslocar essas coisas para seu estado mais extremo de existência, deixando de ser algo comum para estabelecer sua relação com as coisas ao redor, sua posição no mundo.

Suas instalações são responsivas e estabelecem encontros visuais e físicos entre coisas comuns e completamente distintas, objetos naturais e industriais, deixando que as coisas falem por elas mesmas, rejeitando uma interpretação prévia ou enquadramento da subjetividade do objeto dentro de um conceito pré-existente. Os encontros materiais dos trabalhos de Suga criam pontos de sinergia que ativam 
experiências próprias dos objetos e suas relações com o universo, ativando uma espécie de dimensão anímica do objeto, a partir do momento que ele permite que os elementos falem por si mesmos. Kishio Suga buscou retirar o ser humano de uma posição central em relação ao mundo, apreendendo o universo tal como ele é sem opô-lo à condição humana, mas buscando reconciliar a sociedade e seu espírito com a presença concreta dos elementos, reiterando a simbiose de todos os seres que compõem o universo. Em seus trabalhos está contida uma redução das fronteiras entre natureza e artifício, entre elemento natural e artificial. A ação humana e a ação da natureza se imbricam e os objetos fabricados ressoam junto das coisas encontradas ou preexistentes.

Buscando deslocar pontos de referência que separam e hierarquizam humanidade e natureza, e que separam as diferentes culturas, evidencio os efeitos das palavras みずから (mizukara), uma força pensada, em que você mesmo decide fazer sozinho (que traduziria a palavra nature); e おのずから (onozukara) uma força não pensada, sem força nenhuma, que acontece de acordo com o curso das coisas, o raciocínio da natureza (com significado semelhante a shizen). Essa relação se da na constituição de instalações híbridas que evidenciam a ação humana imersa em um conjunto de elementos naturais e artificiais que são expostos de forma que ressoam uma intenção própria da matéria (onozukara).

Através de viagens realizadas ao Japão e ao sertão do Ceará constituí trabalhos elaborando uma poética que possibilita à matéria falar por si, entendendo o gesto artístico como intermediação entre elementos, tempos e narrativas. Por meio de vídeo-performances e site-specific que posteriormente inspiraram a criação de instalações onde as cosmovisões japonesas e sertão-cearenses foram conjugadas formulando espaços de simbiose entre matéria orgânica e artificial, entre visões distintas sobre o espaço, a natureza e o espírito da matéria. Aglutino práticas estéticas dentro desses dois universos referenciais, a fim de constituir relações e traçar narrativas históricas que deflagrem aproximações por meio do estranhamento. Constituindo uma possível ressignificação das relações com (e 
interpretação sobre) o entorno, o estranhamento cria a potência do pensamento, atuando no campo simbólico, desordenando-o.

Nesse sentido, a dança de imagens anacrônicas de Warburg é um importante ponto de partida, que possibilita compreender que tempos e espaços distintos podem residir lado a lado. Também o entendimento da natureza e do meio ambiente sob uma perspectiva anímica contribui com esse pensamento, ao expressar uma visão de mundo em que toda a matéria, tempos e camadas estão em um mesmo plano regido por uma dimensão cósmica, espiritual.

Restringi meu olhar a um único e diverso sertão localizado na região do Cariri Cearense, Sítio Pilar, Assaré, Crato, Serra do Quincuncá e Chapada do Araripe, locais situados lado a lado, ao sul do Ceará e que marcaram a trajetória de meus familiares maternos, que nasceram e viveram nesses locais. Essas áreas que situo foram definidas pela presença indígena, que fundou a cultura local através de um povoamento que envolveu muita luta e resistência. A palavra "cariri" é a principal designação de línguas indígenas do sertão a qual vários grupos pertencem, como os Kariús, que se autodenominavam Quincu, possivelmente em referência a Serra do Quincuncá, onde nasce o rio Cariú. As nações Icós, Cariris, Cariús e Caratiús, que circulavam pela região da Vila Miranda (atual região do Crato), se uniram contra as guerras travadas pelos colonos catequizadores. Segundo o historiador Pompeu Sobrinho, as nações indígenas ligadas à família Cariri se originaram de grupos indígenas da Ásia que atravessaram o Pacífico. Parte do grupo, se distribuiu pela América do Norte, outros adentraram os Andes e parte deles se estabeleceram na atual região do Crato, vindos pelo Rio Amazonas e Rio Tocantins.

O povoamento do Cariri envolve muitas lendas, especialmente indígenas. Acreditase que a Chapada do Araripe é um mar subterrâneo represado pela Pedra da Batateira, que seria chamada de Mãe D’Água e que se um dia essa pedra rolar todo o vale será inundado, libertando uma serpente gigante que irá devolver a terra dos indígenas escravizados pelos brancos. Nessa chapada, encontra-se um sítio arqueológico com inúmeras pinturas rupestres, que a arqueóloga Rosiane Limaverde (2007) acreditou tratar-se de um santuário pré-colonial, que foi utilizado 
com funções ritualísticas. Na superfície das pedras, existem gravuras talhadas com um ícone que se repete, o qual Limaverde interpretou ser uma ave que se assemelha ao tuiuiú ou jaburu, uma espécie que vive apenas em locais úmidos como o Pantanal. Há também pinturas que são similares a serpentes. Esses dois registros podem estar ligados ao mito indígena da Mãe D’Água e a real presença de água em abundância nessa região no passado.

Trabalho, portanto, com as interseções que são narradas entre o campo do imaginário e dos acontecimentos, em um cruzamento em que não se distingue quais imaginações aconteceram, enfim, e quais passagens reais são pura imaginação. Passo, então, a me narrar desde o sertão do Ceará, cidade de Assaré, onde meu avô Filemon plantava algodão, minha avó Carmelina tecia o fio do algodão no fuzo, as linhas se tornavam a rede em que dormiam, a roupa que vestiam. Com a seca sertaneja e o investimento governamental na condução da mão-de-obra nordestina para o sudeste retiraram-se para São Paulo e, três meses após sua vinda, minha avó é atropelada por não saber atravessar a rua, corpo espalhado na concretude das vias que não param, a pele sobreposta pelo cimento. Meu avô passou a trabalhar em obra, construir com concreto não só as casas, mas seu corpo de dedos duros de cimento em baixo das unhas, o qual pegava do mesmo modo que tocou o barro que usava para construir sua casa de taipas. Desde a casa e do corpo, o sertão começa e termina no barro.

O Japão também começa e termina no barro; o barro úmido, a lama das plantações de arroz de onde, segundo o pai dos estudos folclóricos japoneses, Kunio Yanagita, estaria a chave para a compreensão do espírito nipônico, dentro das práticas, crenças e rituais dos plantadores de arroz. Também a seca chega à lama nipônica. 0 inverno se faz em forma de sertão, o solo seca de frio e nesse período nada cresce. É nesse momento que as ruínas são observadas, as rachaduras do corpo são abertas no interior das casas. Há uma conexão entre esse frio rigoroso que resseca e o sol rigoroso que seca; entre a vida no frio rigoroso de Tohoku (nordeste do Japão) e a vida no sertão cearense, dificultadas pela ação do clima. Ao mesmo tempo, a presença da tradição indígena em Tohoku e no sertão nordestino brasileiro mantém 
esses dois nordestes conectados de algum modo à práticas ancestrais. Talvez ai esteja a resiliência dessas regiões assoladas por climas árduos.

Essa resiliência do barro é a minha intercessora. Na lama formada pelo barro coberto de neve do vale de plantadores de Nantan-shi, interior de Kyoto, Japão, onde participei da residência Rice Valley Project, em 2017, encontrei com a minha avó. Desloquei-me para muito longe do sertão cearense para deflagrar associações que desmembram um entendimento linear sobre as culturas e sobre a vida. 0 gelo secou em meu corpo e senti-me profundamente quente em meio a paisagem branca. Caminhei até o antigo templo do vilarejo, na parte alta da floresta. Utilizei um vestido branco que foi costurado por minha avó, entretecido por ela, com o algodão plantado pelo meu avô. Para misturar-me à paisagem caminhei criando rastros na neve intocada que, nesse momento, já chegava até a altura do meu joelho. Para sentir o calor de minha avó e da paisagem, me fundi a elas. 0 gelo, sobre meu corpo descoberto, queimava a pele e me conduzia ao calor intenso do sertão. A permanência dela se fez: Este é o meu corpo, este é o seu corpo.

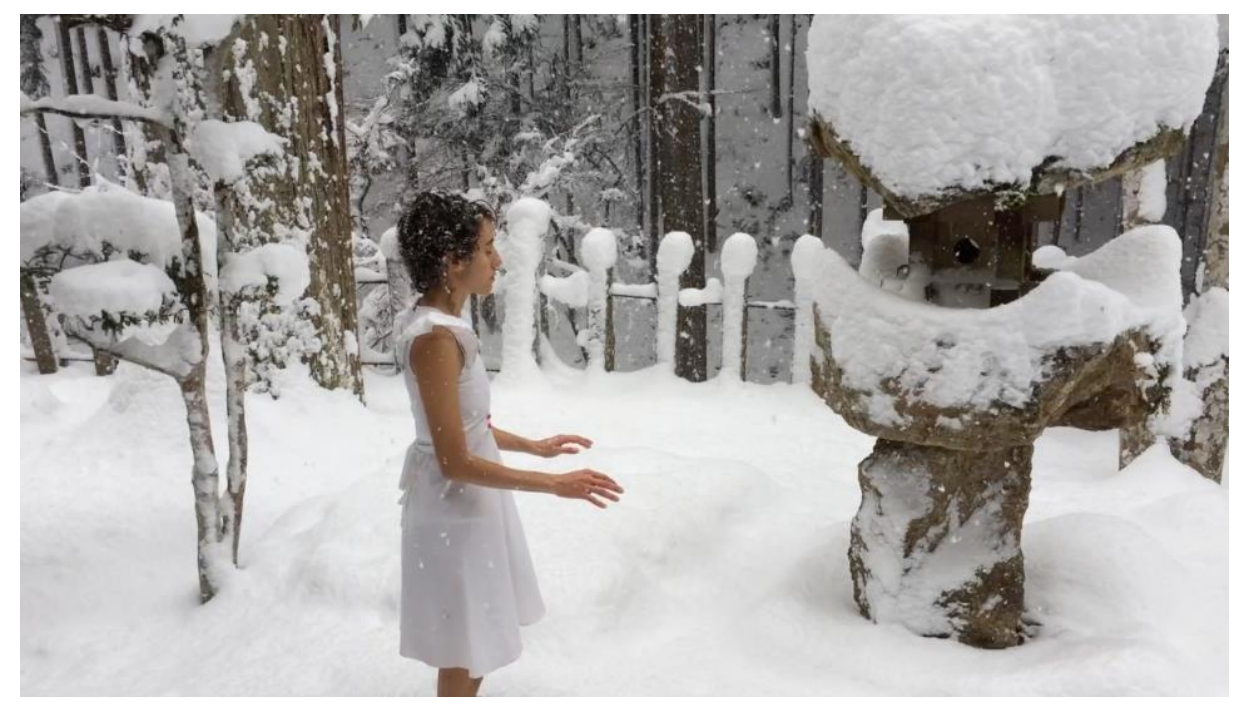

Autor: Anais-karenin; Título: Este é o meu corpo, este é o seu corpo; Técnica: Fotoperformance; Dimensões variáveis; Fonte: elaborada pela autora.

Um ano depois desse trabalho cheguei ao Assaré-Ceará, sertão onde os fios de Carmelina foram tecidos manualmente, onde teceu sua vida. Na casa de barro, semiarruinada e abandonada em meio a seca, reativei memórias contadas. Meu avô, que 
me acompanhava, ao ver o açude seco se colocou de joelhos a simular uma lavação de roupas, como se fosse avó Carmelina presente:

Meu avô, Filemon: Ó, fica aí que eu vou fazer o papel da tua mãe.

Minha mãe, Cecília: Vá lá! Tome cuidado pra não escorregar. Olhe sempre pra ver se não tem uma cobra! Ê dona Carmelina, não tá doendo as costas mulher?

Filemon: Eu tô lavando a ropa, mulher, pra pode i fazê a comida pros menino.

Cecília: Ô mulé, tu qué ajuda?

Filemon: Não, precisa não, quando o Filemon chega ele me ajuda.

Cecília: Ô mulher, já tá bom de esfregar essas ropa, você tá deixando elas muito branca assim.

Filemon: Chama a Maria pra vim busca as trouxa de ropa que eu vô levá a lata d'água. Cecília: Tá bom! Tu trouxe coisa pra come muié?

Filemon: Não, eu cumi tapioca quando sai de casa! Ô Filemon! O Filemon num aparece! iv
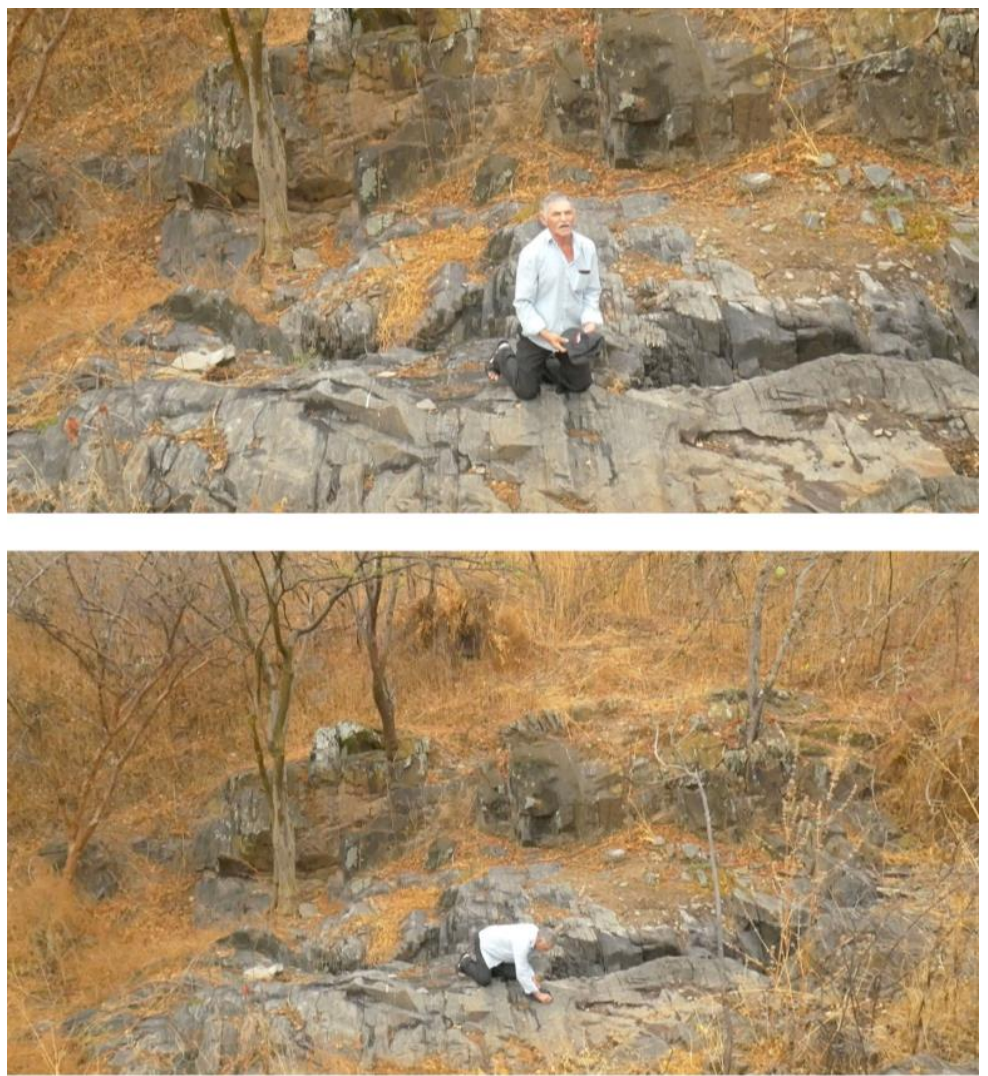

Autor: Anais-karenin; Título: Aonde ela sentou os pés; Técnica: Fotografia; Dimensões variáveis; Fonte: elaborada pela autora. 
Antes de se levantar, meu avô se abaixa e beija a pedra: "Vou da um beijo nessas pedra. Aonde ela sentou os pés". Se dá aí mais uma foto-performance de Carmelina: Aonde ela sentou os pés.

A partir desses encontros com as diversas faces do barro, entrelaçadas por experimentações artísticas que transpuseram dimensões de cultura, território e vida, a dimensão animista ganha forma. De acordo com o animismo presente no xintoísmo, prática espiritual muito antiga na cultura japonesa, as divindades, que são múltiplas, podem habitar qualquer lugar e qualquer forma. Inclusive algumas árvores antigas que ficam nas florestas ao redor do santuário, que são consideradas habitações de divindades. Nelas, uma corda é amarrada formando um shimenawa, que indica que ali vive um Deus guardião da floresta e que aquela árvore nunca poderá ser cortada. Ali é possível perceber o intenso vínculo que há entre a prática espiritual e o cuidado com o ambiente, o vínculo do corpo com a matéria ao redor constituída de vida. Assimilo essa à fé sertaneja, onde vi árvores secas, escolhidas entre tantas, onde fitas, velas e santos eram depositados. 0 chão batido de terra, a cerâmica batida de barro, a vela acessa em meio ao calor intenso, o corpo entregue ao imenso céu onde a fé ganhava força para resistir junto ao ambiente, para ultrapassar junto ao solo mais um verão, e brotar verde.

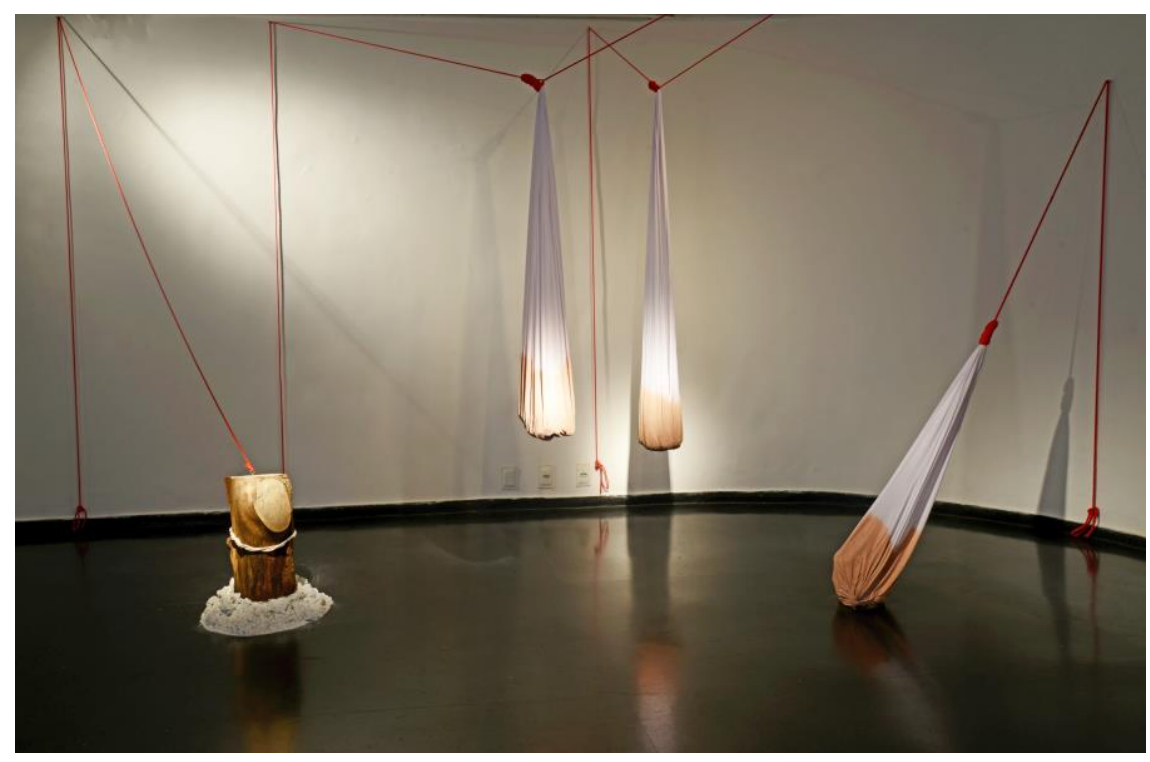

Autor: Anais-karenin; Título: Distance Nature: God is under concrete; Técnica: Instalação; Dimensões: 1,5x3x5m; Fonte: registro por George Magaraia. 
A partir desses cenários que a instalação Distance Nature: God is Under concrete foi realizada. Utilizando três formas em tecido branco, que suspendem $15 \mathrm{~kg}$ de barro cada, junto com um tronco de árvore cortado em que há uma amarração shimenawa. Tanto o barro quanto o tronco são suspensos do chão, ou por estarem elevados ou por terem sua relação intermediada pela cal branca, material da construção civil, tratando da dimensão intocada da natureza e do cosmos dentro dos sistemas de pensamento que cindem e categorizam a vida, que separam, subdividem e hierarquizam a diferença ignorando os sistemas de equilíbrio cosmopolíticos.

A avó que senti na neve nipônica, onde conheci o $M a$, senti também nessa seca cearense, onde entendi o Ma. 0 silêncio espiritual, quase ritualístico, que me habita, habitava também a minha avó sempre muito calada, e todo o sertão sempre com pouco assunto, e habita o interior do Japão em sua paisagem quieta das montanhas. Toda essa interioridade, esse silêncio, deve ser também travessia das origens indígenas dos povos. 0 interior, físico e simbólico, que é sempre o nosso campo de repouso. Somente esse intervalo interno pode conectar pontos tão distantes.

Buscando desvendar simbolicamente o sertão, chego na palavra "interioridade". À inegável quietude sertaneja, o silêncio das terras vastas, a distância quieta e extensa que há entre as coisas, a demora da chuva, a semente internalizada no solo que se nega a brotar, a água que repousa no interior dos cactos, as casas de barro que abrigam a sombra. A etnia Cariri foi assim nomeada pois essa palavra significa "quieto", “calado", e expressa a característica interiorizada da população indígena, da qual os sertanejos desse sertão Cariri descendem. Talvez por haver tanta luz as coisas se escondem, talvez por haver muito sol as manifestações se interiorizam para economizar forças, a água se esconde por baixo da Pedra da Batateira.

O sertão é um grande intervalo, um vasto espaço in-between que abriga a transitoriedade e a quietude. Essa intersecção enorme sertaneja é a materialidade do $M a$, a não-forma do $M a$. É o espaço em sua vastidão misteriosa e desconhecida, onde pode haver indígena, caboclo, jesuíta, asiático e colono. É o campo de atuação múltipla e sem fronteiras, a impermanência do zen. No meio do sertão estão apenas 
os espíritos ancestrais que saem na noite como bolas de fogov ${ }^{\mathrm{v}}$. Apenas a ritualística de uma geografia ainda não compreendida.

O kanji 間 $M a$ é utilizado com diversas significações, a depender do kanji que o acompanha, e pode ser interpretado como um luar surgindo através da fenda de um portão, uma luz informe que preenche um espaço entre duas estruturas rígidas, a luz que brota da parte interna e escura que se faz entre duas coisas. Nesse sentido, o conceito não diz respeito apenas a uma área mensurável, mas denomina também um "espaço imaginário", onde tudo pode ser concebido em um tempo transitório, onde a passagem não é pura, mas uma mistura de luz e sombra, de opostos.

Quando você me pergunta sobre terrorismo e situação política, eu volto novamente a falar sobre Butoh MA, 'estar entre' (in between). Eu penso que, no futuro todos seremos uma mistura, uma mescla entre europeus, japoneses, asiáticos, americanos, africanos, e o mesmo se dará no plano das religiões. Talvez, então em todo o mundo haverá paz (ENDO, 2005, p. 13).

A ação humana, se não apartada da natureza cósmica, pode ser compreendida como a ação do vento, como campo de repouso. Destituindo-se de uma identidade, de uma ideia definida de ser, a fim de chegar ao deslocamento e habitar o espaço transitório Ma. Romper fronteiras pode significar expandi-las, habitá-las, compreendendo que tudo é transitório, tanto os lugares quanto a compreensão sobre esses lugares, coisas e seres. Tudo é regido pela impermanência em fluxo constante, onde nada é suficientemente sólido, onde a ruína acontece, onde os opostos invertem seu lugar o tempo todo. A abstração, a imaginação, o campo dos sonhos, as memórias, têm o potencial de constituir a realidade como uma narrativa incompleta e cambiante, em que o todo é apenas a metade. (一時的) significa temporalidade, impermanência, e ratifica a passagem, a mudança, os intercâmbios e os deslocamentos de perspectiva como uma proposta para lidar com as variadas dimensões do corpo e do espaço em sua potência de multiplicidade e singularidade, que permeia o passado e o presente, a forma e a não-forma, o natural e o artificial, constituindo-se como um entremundos. 


\section{Bibliografia}

KATO, Shuichi. Tempo e espaço na cultura japonesa. São Paulo: Editora Liberdade, 2011.

LATOUR, Bruno. Politics of nature: East and West perspectives. Ethics \& Global Politics, Paris, v. 4, n. 1, 2011.

LIMAVERDE, Rosiane. Os Registros Rupestres da Chapada do Araripe. In: III ENCONTRO DO IPHAN E ARQUEÓLOGOS, 2007, Florianópolis.

MARCON, Federico. Without nature: thinking about the environment in Tokugawa Japan. In: Rethinking Nature in Japan: from tradition to modernity. Veneza: Edizioni Ca' Foscari - Digital Publishing, 2017.

MEGGERS, Betty J. Archaeological evidence for transpacific voyages from Asia since 6000 BP. Estudios Atacameños, Chile, n. 15, 1998.

MICHAUD, Philippe-Alain. Aby Warburg e a imagem em movimento. Rio de Janeiro: Ed. Contraponto, 2013.

OKANO, Michiko. Ma - a estética do “entre”. Revista USP, São Paulo, n.100, 2014

RAG0, Margareth. Prefácio In: A invenção do Nordeste. São Paulo: Cortez Editora, 1999.

SEMON, Richard. Dossiê Warburg. Arte\&Ensaios, Rio de Janeiro, n. 19, 2010.

SITTON, David. The Basics of Animism: Spiritual Warfare in Tribal Contexts. International Journal of Frontier Missions, California, v. 15, n. 2, 1998.

SOBRINHO, Pompeu. As origens dos índios Carirís. Ceará: Editora Instituto do Ceará, 1950.

SUGA, Kishio. Kishio Suga. Brochure Kishio Suga. Nova York, v. 1, p 2, 2017.

WARBURG, Aby. Mnemosyne. Dossiê Warburg. Rio de Janeiro, Arte\&Ensaios, n. 19, p. 125-130. 2010.

\footnotetext{
i MICHAUD, 2013, p. 295.

ii KATO, 2011, p.31.

iii LATOUR, 2011, p. 3 et. seq.

iv Transcrição literal do diálogo entre minha mãe e meu avô, que foi registrado em vídeo.

v Crença popular do sertão de que os espíritos se manifestam como bolas de fogo à noite.
}

Recebido em: 14/11/2018

Aprovado em: 16/11/2018 